\title{
Students' Perspectives as Providers and Receivers of Peer Formative Feedback on Writing
}

\author{
Mohammed Abdullah Alharbi ${ }^{1}$ \\ ${ }^{1}$ Department of English, College of Education, Majmaah University, Majmaah, Saudi Arabia \\ Correspondence: Dr. Mohammed Abdullah Alharbi, Department of English, College of Education, Majmaah \\ University, Majmaah, Saudi Arabia. E-mail: maalharbi@mu.edu.sa
}

Received: May 4, 2021

doi:10.5430/wjel.v11n2p1
Accepted: May 20, $2021 \quad$ Online Published: May 31, 2021

URL: https://doi.org/10.5430/wjel.v11n2p1

\begin{abstract}
The current study focused on exploring the benefits and challenges arising from engagement of 40 undergraduates in peer feedback in a writing course from the feedback providers' and receivers' perspectives. The data was collected from students through a survey and follow-up interviews at the end of two rounds of peer feedback: Round 1 (20 students acting as feedback providers while 20 as receivers) and Round 2 (reserving the roles of students). The findings revealed several benefits of peer feedback for both providers and receivers, which are synthesized under three major themes: being beneficial for students' learning and writing, fostering students' positive feelings and engaging students in reviewing and revising strategies. Despite its benefits, peer feedback is of several challenging concerns for providers and receivers. For providers, they are challenged by their lacking feeling of comfort and low self-confidence as well as lacking certainty about the quality of their feedback. For receivers, they are challenged by their doubts about the reliability of peer feedback and difficulty understanding some feedback as well as the poor quality of records of oral feedback. The study, therefore, provides important pedagogical implications for effective peer feedback practices in writing classrooms.
\end{abstract}

Keywords: feedback provider, feedback receiver, peer feedback, L2 writing

\section{Introduction}

Peer/group feedback on second language (L2) and foreign language (FL) writing has been the focus of extensive research investigation. Research on peer feedback has mainly focused on several aspects of peer feedback, including the patterns of feedback based on analyzing the language functions and foci of feedback (e.g.,Villamil \& De Guerrero, 1996; De Guerrero \& Villamil, 2000; Hanjani \& Li 2014; Gaynor 2020). These studies concluded that as learners engage in peer review of writing, they formulate their peer feedback using different language functions (e.g., questioning, suggestion, evaluation and so on) and pay attention to global (e.g., content) and local issues (e.g., language) in their writing. Research has also explored the role of integration of technological tools in facilitating peer feedback activities in writing classrooms (Bradley, 2014; Liou \& Peng, 2009; Liu \& Sadler,2003). Results of these studies are indicatives of the facilitative role of technological tools as platforms for peer feedback.

Despite the large volume of research on peer writing in undergraduate writing classrooms, what remains unexplored is how students view peer feedback from the perspectives of feedback providers and receivers. Although studies acknowledge the role of students as important participants in formative assessment practices, including peer feedback, their perspectives on peer feedback practices have not well explored in earlier research (Bader et al., 2019). Review papers on peer feedback practices as part of formative assessment in writing (Evans, 2013; Lopez-Pastor and Sicilia-Camacho, 2017) point at the less attention paid by research to students' perspectives on peer feedback practices. According to these review papers, even though studies have shed light into students' perception of peer feedback, investigation of peer feedback has been restricted to surveys and to feedback receivers' perception of feedback. This, therefore, suggests the need for a thorough investigation of peer feedback from the perspectives of student providers and receivers. In responding these gaps and needs in research on peer feedback, the current study aimed to answer the following research questions:

What are the perceived learning opportunities afforded by peer feedback as part of formative assessment of written assignments from provider and receiver perspectives? 
What are the major challenges encountered by the students in peer feedback from provider and receiver perspectives?

\section{Literature Review}

\section{Benefits of peer feedback from providers' and receivers' perspectives}

The literature review points at several benefits of peer feedback for feedback providers. First, student providers assume the role of readers of texts of classmates, similar to their own texts, respond to them and evaluate them (Cho \& MacArthur, 2011; Holliway \& McCutchen, 2004; Kazemi et al.,2018). Moreover, besides critical judgment of peers' assignments from the perspectives of evaluators, student providers become more responsible for learning, actively reflect on their own assignments and better understand the standards of assignments (Cho \& MacArthur,2011; van Popta et al., 2017).

As a result of giving peer feedback, student providers can improve their own work even before receiving feedback from peers by transferring ideas generated through feedback-giving to their work and by exposure to peers' work (Kwok, 2008; Ion et al. 2018; Nicol et al., 2014). They also become aware of the problems and issues in their own writing and learn from peers' writing by comparing peers' writing to their writing (Huisman, Saab, van Driel \& den Broek, 2018). Giving feedback is an opportunity for providers to learn from reading and evaluating peers' writing about their writing (Kazemi et al., 2018; Tian \& Li 2019), reflect on their own writing and develop a better understanding of the quality of their writing (McConlogue 2015). In other words, giving feedback enables student providers to critically reflect on their texts or obtain critical insights into their own writing (Liu et al., 2001). The result of giving feedback is its indirect effect on student providers' writing performance (Cho \& MacArthur, 2011; Holliway \& McCutchen, 2004).

Research has also explored peer feedback in relation to student providers' emotions and social relationships. As feedback providers, students prefer providing positive feedback rather than negative feedback because positive feedback plays a role in encouraging receiver peers, creating a friendly atmosphere and avoiding embarrassment and conflicts with them (Tian \& Li 2019). Moreover, students use strategies and ways of formulating and giving feedback, such as approaching their audience/readers, toning down their critiques and directness, and avoiding harshness in their comments in order to maintain good relationships with peers (Bradley, 2014). Giving feedback also fosters students' confidence (Kazemi et al., 2018).

Providing feedback engages students in different cognitive and metacognitive processes such as detecting or identifying problems in their peers' writing, diagnosing or interpreting them and providing solutions in the form of revisions (Cho \& MacArthur, 2011) as well as critical thinking, mentoring and regulation (Liu et al., 2001). Besides, providers of feedback assume active roles in the learning process, became more responsible and committed to the task, practice the language, enjoy acting as decision-makers and evaluators (Kwok, 2008; Ion et al. 2018) and learn how to construct their comments (Kazemi et al., 2018). It also requires students to provide explanations of the issues and problems in their peers' writing. This, in turns, enables providers to clarify and make their points explicit to peers (Cho \& MacArthur, 2011; Nicol, 2009). Student providers become aware of the role of providing peer feedback in improving their reviewing skills (Bader et al., 2019).

Several scholars have explored peer feedback from receivers' perspectives. Findings have revealed several potential benefits of peer feedback for receivers. This includes revising assignments, improving specific areas of writing (e.g., how to put numerical data) and being a source of motivation for them (Nicol et al.,2014). Student receivers also become aware of the role of feedback, incorporate feedback in revising their writing, enhance their active learning, use cognitive and metacognitive strategies and improve their integration of knowledge in writing and acceptance of others (Ion et al., 2018).

For student receivers' feelings, students most often desire their peer comments or feedback on grammatical issues in their writing, vocabulary, clarity and development of ideas and fluency (Kwok, 2008). Moreover, they prefer receiving negative feedback than positive feedback, especially when it is provided in the written forms. They also have positive attitudes towards peer feedback by valuing both written and oral feedback for being accurate and objective (Tian \& Li, 2019).

According to Bader et al. (2019), most students are satisfied about peer feedback as informal learning beyond the classroom context. Students also use various strategies in acting upon peer feedback: following exactly the same points delivered through feedback, going beyond the points of feedback, making major and minor revisions and incorporating most peer suggestions in writing (Bader et al., 2019; Tian \& Li, 2019). 


\section{Challenges in peer feedback from providers' and receivers' perspectives}

Previous research has identified several challenging issues and concerns arising from peer feedback for student providers. Student providers are challenged by their perceived low confidence on the accuracy of their feedback. This is because they provide feedback based on their opinions, and some others appear uncertain about their feedback. Other initial concerns about feedback providing are students' first time experience in providing comments on their peers' writing, their initial impressions, such as shyness about the quality and details of their comments (Bradley, 2014).

For feedback receivers, McConlogue (2015) reported some challenges, including interpretation of peer feedback and receiving some inaccurate feedback. Other issues involve student receivers' uncertainty about and perception of the low quality of peer feedback (Cartney,2010), misperception of the power assumed by providers of feedback (Liu \& Carless, 2006) as well as their low confidence on peer feedback (Tian \& Li 2019). Students' mixed perception of peer feedback in writing is due to its less facilitative role in enhancing their writing as perceived by them, the equality of their peers' (feedback providers) and their own status and language proficiency, the inadequate specificity of peer feedback (it does not point at all mistakes in writing) and the insufficient amount of positive feedback on their writing (Maarof et al., 2018).

Of the main challenging concerns about peer feedback as expressed by some student receivers are the poor quality of feedback they received, and the lack of effort in providing constructive feedback. Therefore, engaging more than one student in providing feedback on a single text is necessary to receive good quality feedback (Nicol et al., 2014). Another challenging concern is students' questioning of the ability of peers to give accurate feedback for they are not as knowledgeable and experienced as teachers. Hence, peer feedback may not be viewed by them as constructive and useful directions in the revision process. Moreover, failure of some students to take actions upon some feedback is another challenge, which could be due to their lack of trust on the quality of peer feedback (Bader et al. 2019).

Despite the above literature review on the benefits and challenges in peer feedback from the perspectives of providers and receivers, only a few studies have reported a thorough exploration of this research topic from the perspectives of both (e.g., Ion et al., 2018). Therefor, The current study will shed light on peer feedback as part of formative assessment in the EFL context from students' perspectives as feedback providers and receivers which there is no study has covered in the previous literature.

\section{Methods}

\section{Study setting}

The current study was conducted in a writing classroom at Majmaah university during the first semester of the academic year of 2018. The writing class consists of 40 male students only (due to the male-female separated campuses in the country) who were joining the second level in the English Department. The course introduces students to essay writing (e.g., descriptive, narrative and argumentative essay writing). It is taught by one instructor and classes are delivered using the text book as a reference as well as peer and group writing activities and peer and instructor feedback. The peer feedback activities reported in this study were part of students' formative assessment in the course.

\section{The data collection procedure}

The data collection procedure (Figure 1) was performed following three main stages during which the feedback activities were performed by the students and the data collection was performed by the researcher, who is the instructor of the course. However, prior to the procedure, the students were informed of the peer feedback activities in the course and were trained on how to provide and receive peer feedback through samples during one class. The training session also introduced the students to clear instruction on peer feedback, including the aspects of writing that their feedback should focus on according to the criteria in the task assessment: content, organization and coherence and language, including grammar, vocabulary and mechanics of writing.

In the first and second stages, each group of 20 students (S1-20 \& S21-40) acted as both providers and receivers of peer oral and written feedback on their essays. At the end of each stage, the researcher administered an electronic monkey survey that was developed from earlier research (Kazemi et al. 2018; Ion et al., 2018; Tian \& Li, 2019) and individual interviews with students acting providers and receivers of feedback. So after completing the two stages, each student has been already surveyed and interviewed twice: one time as a provider of and one time as a receiver of peer feedback. The survey, consisting of 27 items to which students responded using the five Likert Scale: Strongly Disagree; Disagree; Neutral; Agree; Strongly Agree, covers three main aspects of providing and receiving feedback or the benefits of peer feedback: its value for learning and writing, its role in fostering students' positive 
affective feelings and its role in engaging learners in reviewing and revision strategies. The individual interview consists of several questions prepared by the researcher according to the focus of the survey and also based on the literature of previous related research (See Appendix).

The third stage involved preparation of the collected data for analyses. In this regard, the individual interviews recorded in the previous two stages were listened to by the researcher carefully. Then, each individual recorded interview was changed into a manual written transcript by the researcher. Then, the transcripts of the interviews with feedback providers and receivers were organized into two separate word files which were later subjected to a thematic analysis. In this stage, the students' responses to the electronic survey were also imported into an excel file for the purpose of preparing it for the SPSS later.


Students (S21-S40) acting as feedback receivers and revising their writing

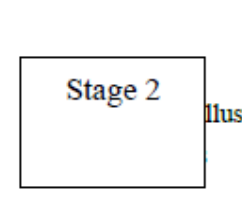

Students (S21-S40) acting as feedback providers or evaluators of their peers' (S1-S20) essays

Students (S1-S20) acting as feedback receivers and revising their writing

Preparing the data for analysis

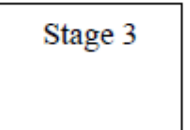



Survey and interviews with feedback receivers

Survey and interviews with feedback providers

Survey and interviews with feedback receivers

Interview transcription and entering the data into SPSS

Figure 1. An illustration of the study procedure

\section{Data analysis}

Prior to administering the survey, the survey was validated by three experts in the same area. Their feedback was taken into account and some items were modified accordingly. Moreover, the reliability of the questionnaire using Cronbach Alpha" was 92.6, which is high. The data collected through the survey was analyzed using a quantitative analysis through SPSS, specifically descriptive statistics, including the number of responses to each item and the mean value $(\mathrm{M})$. The rank of the mean score for each item was also valued within this range: $5-3.67=$ High; 3.66-2.34= Moderate; 2.33-1.00=Low used in most social science research.

For the follow-up interviews with students as both providers and receivers of feedback, the interviews which had been transcribed verbatim were analyzed using a thematic analysis. The thematic analysis was performed by two independent researchers following several steps. First, the transcribed interviews were read carefully several times to get familiar with them. Then, codes were developed based on the survey results: the value of peer feedback, fostering students' positive feelings and engaging learners in reviewing and revising strategies. This coding helped the researcher to find sub-themes that support the results of the survey as an answer to the first research question of the study. For the residuals of the follow-up interviews that did not suit such developed codes, they were read again and line-by-line coding was used based on the literature review. Most of the emergent categories or themes from this step of coding related to the challenges faced by learners in providing and receiving peer feedback were used to answer the second research question.

The process of coding the follow-up interviews was iterative, involving regular meetings and discussions between the two researchers. The themes and sub-themes were compared and disagreements were resolved and the main 
themes generated from the interviews were represented with excerpts extracted from the follow-up interviews.

\section{Findings}

\section{Students' perspectives on peer feedback}

\section{Being beneficial for learning and writing}

The students' responses to the seven statements of the survey (Table 1) are evidence on their perceived value of peer feedback on writing for both providers and receivers. Both providers and receivers perceived the value of peer feedback as a strategy for learning $(\mathrm{M}=3.71 \& 3.82)$ and its role in helping them to engage in active learning $(\mathrm{M}=4.101 \& 3.91)$. Moreover, peer feedback was perceived by student providers and receivers as an opportunity for comparing their previous knowledge with that of their peers $(\mathrm{M}=3.92 \& 3.93)$ and for integrating their knowledge of the subject ( $M=3.20 \& 3.15)$.

The student receivers and providers also reported their highly positive attitudes towards peer feedback, specifically its role in improving their writing $(\mathrm{M}=3.17 \& 4.22)$. Their responses also demonstrate the perceived role of feedback in enhancing the content and idea development $(\mathrm{M}=4.13 \& 4.37)$ and the organization of ideas in their writing (M= $2.81 \& 2.95)$ as well as the language use in their writing $(\mathrm{M}=3.12 \& 4.42)$.

Table 1. Results of students' perceived value of giving and receiving feedback

\begin{tabular}{|l|c|c|c|c|}
\hline Statement & \multicolumn{2}{|c|}{ N } & \multicolumn{2}{c|}{ Mean } \\
\cline { 2 - 5 } & Providers & Receivers & Providers & Receivers \\
\hline Feedback is a useful learning strategy for me. & 36 & 34 & 3.71 & 3.82 \\
\hline Feedback has helped me learn more actively. & 37 & 33 & 4.10 & 3.91 \\
\hline $\begin{array}{l}\text { Feedback has allowed me to compare my previous } \\
\text { knowledge with the knowledge of others. }\end{array}$ & 36 & 38 & 3.92 \\
\hline $\begin{array}{l}\text { Feedback has helped me integrate the knowledge of the } \\
\text { subject. }\end{array}$ & 38 & 37 & 3.20 & 3.15 \\
\hline $\begin{array}{l}\text { Feedback has been significant in improving my writing. } \\
\text { Feedback has helped me to enrich the content of my } \\
\text { writing. }\end{array}$ & 37 & 37 & 3.17 & 4.22 \\
\hline $\begin{array}{l}\text { Feedback has helped me to improve the organization of my } \\
\text { writing. }\end{array}$ & 36 & 39 & 2.13 & 4.37 \\
\hline $\begin{array}{l}\text { Feedback has helped me to improve the language of my } \\
\text { writing. }\end{array}$ & 37 & 39 & 3.12 & 2.95 \\
\hline
\end{tabular}

From the above results, the student receivers' perception of peer feedback and its value in their learning and writing is more positive than that that of student providers in all aspects except for the role of peer feedback in active learning and integrating the knowledge of the subject. Moreover, in all aspects of the value of peer feedback in learning and writing, both student providers and receivers hold a moderately positive perception of the role of feedback in integrating the knowledge of the subject and in improving the organization of ideas in writing since the mean values fall within the range of moderately positive perception (2.34-366). Unlike feedback receivers, feedback providers hold a moderately positive perception of the role of peer feedback in improving their writing and in improving the language of their writing.

The findings obtained from the follow-up interview support the above results of the survey and also offer further elaboration of the role of feedback in enhancing writing from student providers. First, most of them described it as a useful learning process in which they assumed active roles: "I found it really interesting and a kind of" active learning for me because when I was pointing at issues, I found it like: Ok I know this and evaluate my classmates' writing" (Interviewee 23). Secondly, it engaged them in comparing their peers' writing to their own and therefore, they enhanced their writing: "We can always check others' writing and compare it to ours. So it's kind of revision for us" (Interviewee 36). Moreover, when asked about the aspects of writing that providing feedback helped them to enhance in their writing, some of the interviewees stated that they commented on all different issues stated in the instruction: "I think that providing feedback helped me to enhance almost all aspects of my writing" (Interviewee 26), while some others highlighted their focus on content and language issues in writing: "I learned to look at the grammatical aspects as well and the whole content of my writing as a result of providing feedback on my classmates' writing" (Interviewee 10).

For feedback receivers, the follow-up interviews are indicatives of their positive views on the role of peer feedback. 
First, most of the students in the follow-up interview expressed their positive views on the role of receiving peer feedback by describing it as helpful, beneficial, useful and valuable. For instance, as stated by one of them: "I like receiving feedback from my classmates. It's really helpful for me and I improved my learning or knowledge" (Interviewee 7). Moreover, the majority of them agree that the feedback they received helped them to focus on the content and language issues: "The feedback made me realize there was a lot of issues in my content and mistakes that I did not realize when I was writing, which is so good to get to know them especially in my classmates' comments" (Interviewee 1). Only a few interviewees stated that they received few comments from peers on issues related to organization: "I can say that only a few comments I received from peers on organization of my ideas" (Interviewee 18).

\section{Fostering students' positive feelings}

The second important emerging theme from the data is students' feelings upon providing and receiving peer feedback. As shown in Table (2), since the first three items focus on three aspects of students' feelings that are applicable to both providers and receivers, we can see that the role of peer feedback in improving students' acceptance of others is more positively perceived by feedback providers $(M=4.11)$ than feedback receivers $(M=3.12)$. However, student receivers' perception of the role of peer feedback in increasing their confidence in others and their satisfaction of feedback is more positive $(M=3.62 \& 4.17)$ than the perception of feedback providers ( $M=3.13 \& 4.12)$. This result is supported by the follow-up interviews. While the majority of student receivers talked about their enhanced satisfaction and confidence in others as a result of feedback receiving: "As a receiver of feedback, I feel more confident now and satisfied because after reading more comments from peers, I made more changes to my writing" (Interviewee 20), only some of the student providers talked about this in the follow-up interviews: "As a provider of feedback, I am more confident and more satisfied with my feedback" (Interviewee 30).

The students' responses to the other four items of the survey focus on their feelings over providing and receiving positive and negative/critical feedback on writing. When giving feedback, students hold a preference for positive feedback $(M=4.12)$ than negative feedback $(M=2.70)$. This result is elaborated by the follow-up interviews. The preference for positive feedback among providers of feedback is attributed to their avoidance of hurting/damaging their peers' (feedback receivers) feelings/emotions as a result of providing negative and critical feedback on their writing: "When we provide feedback, I think we should not be critical and give negative points because, as you know, we're all humans and make errors" (Interviewee 6).

In contrast, student receivers tend to have a preference for negative feedback $(M=4.01)$ than positive feedback $(\mathrm{M}=2.19)$. This is due to the fact that student receivers seem to be aware of the need for peer feedback that is constructive and that points at the issues in their writing even if it is negative because this will help them to revise and improve their writing: "I would say I like to receive negative and critical feedback from my classmates because ah I mean this is to make my writing better" (Interviewee 31).

Table 2. Results of students' positive feelings over giving and receiving feedback

\begin{tabular}{|c|c|c|c|c|}
\hline \multirow[t]{2}{*}{ Statement } & \multicolumn{2}{|c|}{$\mathrm{N}$} & \multicolumn{2}{|c|}{ Mean } \\
\hline & Providers & Receivers & Providers & Receivers \\
\hline Peer feedback has improved my acceptance of others. & 37 & 38 & 4.11 & 3.12 \\
\hline Peer feedback has increased my confidence in others. & 39 & 39 & 3.13 & 3.62 \\
\hline I am satisfied with peer feedback in this course. & 38 & 37 & 4.12 & 4.17 \\
\hline I like to give positive feedback on my peer's writing. & 37 & Not applicable & 4.12 & Not applicable \\
\hline I like to give negative feedback on my peer's writing. & 36 & Not applicable & 2.70 & Not applicable \\
\hline $\begin{array}{l}\text { I like to receive positive feedback from my peer on my } \\
\text { writing. }\end{array}$ & Not applicable & 39 & Not applicable & 2.19 \\
\hline $\begin{array}{l}\text { I like to receive negative and critical feedback from my } \\
\text { peer on my writing. }\end{array}$ & Not applicable & 39 & Not applicable & 4.01 \\
\hline I like to offer oral feedback on my peers' writings. & 39 & Not applicable & 4.29 & Not applicable \\
\hline I like to offer written feedback on my peers' writings. & 38 & Not applicable & 2.86 & Not applicable \\
\hline I like listening to my peers' oral feedback on my writing. & Not applicable & 38 & Not applicable & 2.91 \\
\hline I like reading my peers' written feedback on my writing. & Not applicable & 39 & Not applicable & 4.31 \\
\hline
\end{tabular}

In this study, the other remaining four items of the survey in focus on students' preferences for the mode of feedback: oral vs. written feedback. From the perspectives of providers, oral feedback is highly preferred $(M=4.29)$ than written feedback $(\mathrm{M}=2.86)$ on their peers' writing. One reason for this higher tendency to offer oral feedback among 
student providers, illustrated by the follow-up interviews, is that oral feedback is often provided in real or face-to-face conversations and given immediately and requires an immediate response from its receiver: "I would prefer to give oral feedback because the feedback is given in talk, immediately and even immediate responses" (Interviewee 3). Another important reason behind their preference for giving oral feedback is the shorter time needed in composing oral feedback in comparison to composing written feedback: "Yup I like to give oral feedback because you know? It takes just a short time to say the feedback or speak it" (Interviewee 19).

On the other hand, being investigated from the perspectives of feedback receivers, written feedback is highly preferred to be received by students $(M=4.31)$ than oral feedback on their writing $(M=2.91)$. Based on the follow-up interviews, why those students prefer written feedback is due to the time offered for student receivers to read and re-read written feedback as opposed to oral feedback: "I prefer online written feedback because of the time. Ah I mean we get the time to read and modify our drafts" (Interviewee 24). Moreover, since written feedback is attached to the exact part of the written text where the issue/error is identified, it becomes easier for student receivers to understand and revise exactly the same issue/error in writing: "I prefer written feedback. I can see the feedbacks and mistakes I made at the same page" (Interviewee 16).

\section{Engaging students in reviewing and revising strategies}

This final part of the survey comprising eight items focuses on perspectives on strategies used by students in giving and receiving peer feedback. From the results in Table (4), in providing peer feedback, students reported their use of several cognitive and metacognitive strategies: careful reading $(M=4.2)$ and careful evaluation $(M=4.25)$ of their peers' writing based on the instruction, highlighting the issues and errors in their writing $(\mathrm{M}=3.81)$ and trying to be clear and specific about the issues and errors in their peers' writing (M3.77). All these strategies reported by student providers of feedback fall within the high mean range. Some of these strategies used by students in providing feedback were also supported by the follow-up interviews. For instance, most of them acknowledged their careful reading of their peers' texts and attempts in understanding them and pointing at the issues from readers' perspectives: "I read and tried to understand the whole text to be able to point at some confusing parts because as a reader, I wanted to understand what the writer was trying to say. Then, I marked the errors or mistakes and gave comment on them" (Interviewee 32). They also talked about their following of the instruction and reference to the course: "I also followed the criteria the doctor gave and I referred to the slides of the course to look at knowledge" (Interviewee 7).

Table 3. Results of students' engagement in reviewing and revising strategies

\begin{tabular}{|l|c|c|}
\hline \multicolumn{1}{|c|}{ Statement } & $\mathrm{N}$ & Mean \\
\hline When giving feedback, I carefully read my peer's writing. & 39 & 4.21 \\
\hline When giving feedback, I evaluate my peer's writing on the criteria and instruction of the course. & 40 & 4.25 \\
\hline When giving feedback, I highlight the issues and errors in my peer's writing. & 37 & 3.81 \\
\hline $\begin{array}{l}\text { When giving feedback, I try to be very specific and clear about the issues and errors in my } \\
\text { peer's writing. }\end{array}$ & 39 & 4.15 \\
\hline When receiving peer feedback, I carefully read or listen to each comment. & 38 & 4.11 \\
\hline $\begin{array}{l}\text { When receiving peer feedback, I evaluate or compare it on the criteria and instruction of the } \\
\text { course. }\end{array}$ & 40 & 3.77 \\
\hline $\begin{array}{l}\text { When receiving peer feedback, I try to understand the issues of my writing stated in the } \\
\text { message of feedback provider. }\end{array}$ & 39 & 3.96 \\
\hline $\begin{array}{l}\text { I have incorporated all or most of the peer feedback in my writing that I found specific and } \\
\text { clear. }\end{array}$ & 39 & 3.98 \\
\hline
\end{tabular}

The above results on receiving feedback illustrate that students also used several strategies in receiving peer feedback. These are careful listening and reading peer feedback $(\mathrm{M}=4.11)$, comparing the feedback to the instruction $(\mathrm{M}=3.77)$, trying to understand the issues in their writing from feedback providers' intent $(\mathrm{M}=3.96)$ and incorporation of most of peer feedback into their writing $(\mathrm{M}=3.98)$. Based on the follow-up interviews, some student receivers stated their attempts in reading and understanding the peer feedback they received on their writing: "As $a$ receiver, I read all comments and made sure that I read each feedback and re-checked and understood it well" (Interviewee 2). Some of them also admitted acting upon or following the feedback in revising their writing: "I tried to follow most of the feedback when I revised my writing" (Interviewee 25). Another strategy identified in the follow-up interview used by some students in receiving peer feedback is responding to feedback in case when they failed to understand it: "When I failed to understand some of peer feedback, I asked them and replied to them" 
(Interviewee 39).

\section{Students' perspectives on the challenging concerns arising from peer feedback}

The findings from the thematic analysis of the follow-up interviews revealed several challenges and concerns arising from the process of providing and receiving peer feedback faced by the students in this study. This section presents the findings as follows:

\section{Challenges in providing peer feedback}

The findings show that feedback providers faced several challenging concerns in providing feedback on their peers' writing. First, some of the interviewees pointed at their lacking feeling of comfort upon providing feedback: "So sometimes, I don't feel comfortable to give feedback, but because we are in academic settings, we have to" (Interviewee 13).

In the follow up-interviews, as feedback providers, some students did not seem confident. When they were asked why they felt so, some of them stated that they are unable to identify the issues and errors in their peers' writing: " $I$ found it difficult to provide feedback because ah mmmm I could not see what the problems are” (Interviewee 34). Another reason behind these students' lacking self-confidence is their English language proficiency: "I just feel so bad. I am not proficient. I am not confident like others. Yeah that's it” (Interviewee 6).

In this study, providing peer feedback on writing also turned out to be of a challenging concern for some student providers due to their fear and uncertainty of the accuracy of their feedback: "For me, sometimes, I was like afraid because I was not sure if my feedback is correct or not" (Interviewee 19). As feedback providers, students had to judge their peers' writing. However, some of the students felt shy to make judgment or evaluation of their peers' writing: "I was really shy to evaluate my friends' writing if it was good or not because this is my nature" (Interviewee 25).

\section{Challenges in receiving peer feedback}

In this study, several challenges in receiving peer feedback were identified. From student receivers' perspectives, peer feedback is challenged by some students' concerns about the reliability of feedback or about the feedback providers' knowledge of the issues in their writing: "So I cannot just follow my peer feedback. I mean how to say- I have some doubt about it" (Interviewee 38). As they were asked why they have such doubt about peer feedback from the receiver perspective, while some interviewees compared their peers (feedback providers) to teachers' or instructors' feedback: "I mean the feedback I get from peers is not as reliable as the one I get from the teacher", others questioned knowledge and expertise of peers as feedback providers: "I mean my peers are like normal readers-like someone who is not expert in this".

The follow-up interviews also revealed that student receivers of peer feedback found it difficult to understand some feedback they received on their writing: "Sometimes, I could not understand what my classmate who give feedback on my writing exactly wants to do. I mean ambiguous" (Interviewee 14). A few student receivers attributed this difficulty in understanding some peer feedback on their writing to the way feedback providers use the language in conveying the intended message to peers: "Sometimes, the language itself of my peers when providing oral and written feedback. I found it difficult to understand" (Interviewee 20).

The findings of the follow-up interviews also demonstrate that as receivers of peer feedback, especially oral feedback, most of the students expressed concerns about peer feedback due to some issues in speaking English (e.g., mispronunciation of some words): "There might be misunderstanding because of the utterance of the words in oral feedback" (Interviewee 4). Even each student receiver was asked to record the oral feedback given by his partner or peer, sometimes, the quality of records appeared to be another challenge for students: "For me, I found that the oral feedback I recorded was not clear because of my mobile recording and also the noise around" (Interviewee 15).

\section{Discussion}

The current study investigated the opportunities for learning afforded by peer feedback from the perspectives of both student providers and receivers of feedback on their writing. The findings obtained from the survey and follow-up interviews with students demonstrated the perceived benefits of peer feedback. Regarding this, both providers and receivers reported their positive perception of the role of peer feedback in enhancing students' learning in general and writing in particular. For students' learning, providing and receiving peer feedback plays a significant role in engaging learners in meaningful and active learning, comparison of their existing knowledge with that of peers and integration of the knowledge of the subject. This particular finding is consistent with a recent study on peer feedback (Ion et al.,2018) that the role of peer feedback in enhancing active learning, developing cognitive and metacognitive 
strategies and improving integration of knowledge is not exclusive to student receivers of feedback, but also inclusive of feedback providers.

For the value of peer feedback in writing, in this study, both student providers and receivers valued peer feedback for it contributed to the quality of their writing, specifically the content, organization and language of their writing though the degree to which students valued this role of peer feedback in their writing somehow differed between providers and receivers and in terms of the aspects of writing. As students provide peer feedback on their classmates' writing, they can improve their writing through transfer of feedback giving to their own writing (Huisman et al., 2018; Nicol et al., 2014). In other words, from providing feedback, students can enhance their own writing (Kazemi et al., 2018; Ion et al. 2018). In this study, transfer of ideas could have occurred in the form of comparison. In other words, providing of peer feedback enables student providers to enhance their own writing by comparing it to the writing of peers (Liu et al., 2001; McConlogue, 2015) that they evaluate and learning from issues or mistakes in peers' writing (Kwok, 2008). For receivers, receiving peer feedback allows them to see their issues/errors from their peers' eyes and fix them.

In this study, exploring peer feedback involves students' feelings over peer feedback from the perspectives of student givers/providers and receivers. Specifically, the role of peer feedback in enhancing students' acceptance of others, satisfaction and confidence in others is realized by both providers and receivers of feedback. Yet, while its role in improving learners' acceptance of others is more highly perceived by feedback providers, its role in increasing satisfaction and confidence in others is more highly perceived by feedback receivers. This finding partly supports what was reported by Kazemi et al. (2018) on the role of peer feedback in raising students' confidence and in enhancing their acceptance of others documented in another study by Ion et al. (2018).

Students' perspectives on peer feedback in relation to their positive feelings also cover providers' and receivers' preference for the nature of feedback: positive or negative and for the mode of feedback: oral or written. For the nature of feedback, student providers highly prefer to give positive feedback for they appear to be aware of maintaining positive relationships with receivers through positive feedback. This result similar to Bradley's (2014) result on strategies used by feedback providers in maintaining good relationships with peers, such as toning down their critiques and directness in their comments and avoiding harshness in their comments. Student providers' preference for positive feedback as opposed to negative feedback is owing to the role of positive feedback in encouraging student receivers to revise their writing, creating a friendly atmosphere and avoiding embarrassment and conflicts (Tian \& Li 2019). For feedback receivers, in contrast, they highly prefer receiving negative and critical feedback, which is somehow similar to the finding of another study (Kazemi et al., 2018). This underlies student receivers' awareness of the role of negative or critical feedback in assisting them to identify and fix the issues in their writing.

For the mode of peer feedback, the finding of this study revealed opposite preferences of providers and receivers of feedback. From the perspectives of providers, oral feedback is highly preferred than written feedback. The reasons inferred from the analysis of the follow-up interviews are its immediacy, requirement of an immediate response from the receiver and the less time consumed in its composition or formulation. On the other hand, this study revealed receivers' preference for written feedback, which is owing to the sufficient time after receiving written feedback, thus allowing receivers to read it several times, understand its message and fix the issues in their writing based on such feedback. This finding is contradictory to the finding of Tian and Li (2019) on student receivers' valuing of both oral and written feedback.

In this study, peer feedback beneficial for it engages learners in using various cognitive and metacognitive strategies: careful reading of peers' writing, evaluating it, highlighting the issues/errors or mistakes in their peers' writing and making attempts to be clear in providing feedback. It also engages students in learning how to compose their feedback, evaluate peers' writing (Kazemi et al., 2018; Kwok, 2008) and identify the issues in their peers' writing (Huisman et al., 2018). All these strategies are indicatives of the value of giving feedback for students' important reviewing skills (Bader et al. 2019). For student receivers, peer feedback engages learners in reading and understanding the intended messages provided by peers through feedback, comparing feedback to the instruction or criteria of the course, responding to feedback and acting upon or incorporating feedback in revising their writing. By so doing, feedback receivers are more likely to enhance their tasks (Ion et al. 2018; Tian \& Li 2019).

The current study also attempted to identify the major challenging issues and concerns arising from peer feedback. From providers' perspectives, peer feedback is challenging for some students due to their lacking feeling of comfort as well as their low self-confidence in providing feedback. This result goes in line with result reported by Bradley (2014) that providers of feedback are often challenged by their low self-confidence, which is attributed by some of 
the students in this study to their inability or failure to identify the problems and issues in their peers' writing. Another reason for their low self-confidence is their English proficiency.

In this study, providing peer feedback on writing appeared to be of a challenging concern for some providers because of their fear and uncertainty of the accuracy of their feedback. Another challenging concern for some student providers is their shyness over providing feedback on their peers' writing. According to Bradley (2014), students acting as providers of feedback may find it challenging to actively engage in the process of providing feedback due to their uncertainty about the accurateness of their feedback provided on their classmates' writing and shyness.

The present study also revealed several challenging concerns arising from peer feedback for student receivers. First, some receivers of peer feedback are challenged by their doubts about the reliability of feedback or about the knowledge of peers who provided the feedback on their writing. This is not new given that some previous studies reported such challenging issue of students' low perceived quality of peer feedback (Cartney,2010; Nicol et al., 2014). However, like the study of Bader et al. (2019), this study reported student receivers' questioning of the feedback providers' abilities to provide accurate feedback, especially since they are not experts.

Other issues faced by feedback receivers are related to their understanding of peer feedback. In other words, some students reported their failure to understand some peer feedback on their writing. This could be interpreted from student providers' language proficiency in English. The way some feedback providers use English for communicating their messages in peer feedback plays an important role in intangibility of feedback among feedback receivers (Maarof et al.,2018). This is more crucial especially in the context of providing oral feedback. In this study, utterances of some words in oral peer feedback represented a challenging concern for some feedback receivers as this might have led to misinterpretation of the intended messages. A final issue related to intangibility of peer feedback is the quality of records used in recording oral feedback. Some students found it difficult to understand the oral feedback recorded by them.

\section{Conclusion}

Based on the above findings, the current study has several pedagogical implications for EFL writing in higher education. First, the use of peer feedback as part of formative assessment of students' performance in writing classroom is important for it benefits both student providers and student receivers of feedback. Secondly, since student providers still face several challenging concerns about giving feedback on their classmates' writing, effective training sessions and instruction on how to evaluate peers' writing and how to provide formative feedback are necessary for students.

In addition, students should be encouraged to act as feedback providers in order to enable them to overcome their fears, shyness and lack of self-confidence in providing peer feedback. When training students in providing feedback, instructors should model oral and written feedback with an emphasis on the simple and clear language used in feedback. Students should be also encouraged to act as peer feedback receivers. They should be trained on how to evaluate peer feedback based on the instruction or the criteria of the writing task in the course, respond to it and integrate the feedback they evaluate as good in their writing.

The current study contributes to previous research on peer feedback as part of formative assessment in the EFL context from students' perspectives as feedback providers and receivers. Despite its rich insights into the opportunities and challenges in providing and receiving peer feedback, the study has several limitations that should be addressed for future research. The investigation reported in the current study focused on students' perspectives on peer feedback. However, the actual peer feedback was not analyzed due to the restricted scope of this paper. Therefore, a future study may build on the findings of the present study by analyzing the actual feedback to triangulate the findings. By so doing, future research may look at the differences or contradictions between actual peer feedback practices: giving and receiving of feedback and students' perspectives on giving and receiving peer feedback. The current study did not use students' reflections not or even records of their thoughts during the process of giving and receiving feedback. Future studies can use this type of data in order to provide enriching insights into what student providers think of when giving peer feedback and how student receivers react to peer feedback once receiving it. Finally, another interesting aspect of this research topic that needs to be investigated in future research is comparison between teachers' perspectives and students' perspectives on peer feedback in writing classrooms.

\section{References}

Bader, M., Burner, T., Hoem Iversen, S., \& Varga, Z. (2019). Student perspectives on formative feedback as part of writing portfolios. Assessment \& Evaluation in Higher Education, 44(7), 1017-1028. https://doi.org/10.1080/02602938.2018.1564811

Published by Sciedu Press 
Bradley, L. (2014). Peer-reviewing in an intercultural wiki environment-student interaction and reflections. Computers and Composition, 34, 80-95. https://doi.org/10.1016/j.compcom.2014.09.008

Cartney, P. (2010). Exploring the use of peer assessment as a vehicle for closing the gap between feedback given and feedback used. Assessment \& Evaluation in Higher Education, 35(5), 551-564. https://doi.org/10.1080/02602931003632381

Cho, K., \& MacArthur, C. (2011). Learning by reviewing. Journal of Educational Psychology, 103(1), 73-84. https://doi.org/10.1037/a0021950

De Guerrero, M. C., \& Villamil, O. S. (2000). Activating the ZPD: Mutual scaffolding in L2 peer revision. The Modern Language Journal, 84(1), 51-68. https://doi.org/10.1111/0026-7902.00052

Evans, C. (2013). Making sense of assessment feedback in higher education. Review of educational research, 83(1), 70-120. https://doi.org/10.3102/0034654312474350

Hanjani, A. M., \& Li, L. (2014). Exploring L2 writers' collaborative revision interactions and their writing performance. System, 44, 101-114. https://doi.org/10.1016/j.system.2014.03.004

Holliway, D. R., \& McCutchen, D. (2004). Audience perspective in young writers' composing and revising. In Revision Cognitive and Instructional Processes (pp. 87-101). Springer, Dordrecht. https://doi.org/10.1007/978-94-007-1048-1_6

Huisman, B., Saab, N., van Driel, J., \& van den Broek, P. (2018). Peer feedback on academic writing: undergraduate students' peer feedback role, peer feedback perceptions and essay performance. Assessment \& Evaluation in Higher Education, 43(6), 955-968. https://doi.org/10.1080/02602938.2018.1424318

Ion, G., Sánchez Martí, A., \& Agud Morell, I. (2019). Giving or receiving feedback: which is more beneficial to students' learning? Assessment \& Evaluation in Higher Education, 44(1), 124-138. https://doi.org/10.1080/02602938.2018.1484881

J. W. Gaynor. (2020). Peer review in the classroom: student perceptions, peer feedback quality and the role of assessment. Assessment \& Evaluation in Higher Education, 45(5), 758-775. https://doi.org/10.1080/02602938.2019.1697424

Kazemi, M., Abadikhah, S., \& Dehqan, M. (2018). EFL Students' Perceptions of Teacher Feedback and Intra-Feedback in Writing Essays. Khazar Journal of Humanities and Social Sciences, 21(2), 26-49. https://doi.org/10.5782/2223-2621.2018.21.2.26

Kwok, L. (2008). Students' perception of peer evaluation and teachers' role in seminar discussions. Electronic journal of foreign language teaching, 5(1), 84-97.

Liou, H. C., \& Peng, Z. Y. (2009). Training effects on computer-mediated peer review. System, 37(3), 514-525. https://doi.org/10.1016/j.system.2009.01.005

Liu, E. Z. F., Lin, S. S., Chiu, C. H., \& Yuan, S. M. (2001). Web-based peer review: the learner as both adapter and reviewer. IEEE Transactions on education, 44(3), 246-251. https://doi.org/10.1109/13.940995

Liu, J., \& Sadler, R. W. (2003). The effect and affect of peer review in electronic versus traditional modes on L2 writing. Journal of English for academic Purposes, 2(3), 193-227. https://doi.org/10.1016/S1475-1585(03)00025-0

Liu, N. F., \& Carless, D. (2006). Peer feedback: the learning element of peer assessment. Teaching in Higher education, 11(3), 279-290. https://doi.org/10.1080/13562510600680582

López-Pastor, V., \& Sicilia-Camacho, A. (2017). Formative and shared assessment in higher education. Lessons learned and challenges for the future. Assessment \& Evaluation in Higher Education, 42(1), 77-97. https://doi.org/10.1080/02602938.2015.1083535

Maarof, N., Yamat, H., \& Li, K. L. (2011). Role of teacher, peer and teacher-peer feedback in enhancing ESL students' writing. World Applied Sciences Journal, 15(Innovation and Pedagogy for Lifelong Learning), 35-29.

McConlogue, T. (2015). Making judgements: investigating the process of composing and receiving peer feedback. Studies in Higher Education, 40(9), 1495-1506. https://doi.org/10.1080/03075079.2013.868878

Nicol, D., Thomson, A., \& Breslin, C. (2014). Rethinking feedback practices in higher education: a peer review perspective. Assessment \& Evaluation in Higher Education, 39(1), 102-122. https://doi.org/10.1080/02602938.2013.795518

Published by Sciedu Press 
Tian, L., \& Li, L. (2018). Chinese EFL learners' perception of peer oral and written feedback as providers, receivers and observers. Language awareness, 27(4), 312-330. https://doi.org/10.1080/09658416.2018.1535602

Villamil, O. S., \& De Guerrero, M. C. (1996). Peer revision in the L2 classroom: Social-cognitive activities, mediating strategies, and aspects of social behavior. Journal of second language writing, 5(1), 51-75. https://doi.org/10.1016/S1060-3743(96)90015-6

\section{Appendix: Questions for the follow-up interviews}

1. What do you think of giving/receiving peer feedback in this course?

2. In what ways did giving/ receiving peer feedback help you in your writing?

3. What aspects of writing were the focus of peer feedback you provided/received?

4. As providers/receivers of peer feedback, which do you like more: positive or negative feedback and why?

5. As providers/receivers of peer feedback, which do you prefer: oral or written feedback and why?

6. What are the main challenges did you face in providing/receiving peer feedback in the course?

\section{Copyrights}

Copyright for this article is retained by the author(s), with first publication rights granted to the journal.

This is an open-access article distributed under the terms and conditions of the Creative Commons Attribution license (http://creativecommons.org/licenses/by/4.0/). 